\title{
Edgar Iván Espinosa Martínez
}

Maestro en Sociología Política y candidato a doctor en Historia Moderna y Contemporánea por el Instituto de Investigaciones Dr. José María Luis Mora.

\section{Resumen}

En el siguiente artículo se presenta una visión que aspira a ser íntegra respecto al corpus historiográfico nuevoleonés producido entre 1867 y 1996. Se propone detectar las etapas y periodos durante este gran lapso a partir de las condiciones institucionales, tendencias académicas y posicionamientos de autores que han caracteriza- do la práctica historiográfica en la entidad. Asimismo, se distingue a los historiadores más representativos y sus respectivas obras, las cuales han marcado ciertas pautas en la forma de investigar y escribir la historia regional del noreste mexicano.

Palabras clave:

Historia, historiografía, Monterrey, noreste, Nuevo León, región histórica.

Fecha de recepción: Fecha de aceptación:

noviembre de 2005 junio de 2006 


\title{
Historiographic Practice in Nuevo León. An Archaeology of Regional Historical Knowledge, 1867-1996
}

\author{
Edgar Iván Espinosa Martínez
}

MA in Political Sociology and doctoral candidate in Modern and Contemporary History at the Instituto de Investigaciones Dr. José María Luis Mora.

\begin{abstract}
The following article provides an integral view of the historiographic corpus of Nuevo León produced between 1867 and 1996. It attempts to detect the stages and periods during this long period of time of institutional conditions, academic trends and positions of authors that

have characterized historiographic practice in the state. It also identifies the most representative historians and their respective works, which have established certain guidelines in the way of investigating and writing the regional history of the Mexican northeast.
\end{abstract}

Key words:

History, Historiography, Historic Region, Monterrey, Northeast, Nuevo León. 


\title{
La práctica historiográfica en Nuevo León. Una arqueología del conocimiento histórico regional, 1867-1996
}

\author{
Edgar Iván Espinosa Martínez
}

\section{A la memoria de Isidro Vizcaya}

(1917-2005)

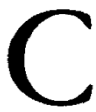

omo toda producción de algún tipo de conocimiento, el que se ha acumulado a partir de la investigación y el estudio de la historia en distintas latitudes de México posee su particularidad desde el punto de vista arqueológico. Tanto localizar autores y obras e inferir las preocupaciones que los impulsaron a escribirlas, como redescubrir el ámbito intelectual, académico y cultural en el cual irrumpieron y detectar posicionamientos teóricos y/o metodológicos estén explícitos o implícitos, así como saber la utilidad que tenían, nos advierte de las variadas dimensiones de la historiografía regional mexicana. Para reconstruir arqueológicamente el proceso de un discurso acerca del pasado, como aquel que da cuenta de la experiencia histórica nuevoleonesa, es necesario arriesgar un juicio que indique el posible inicio de una historiografía regional. Es decir, el reto está en la búsqueda y detección de un recorrido discursivo -según lo planteara Foucault- que configura el conocimiento que sobre el pasado de una región ha realizado la investigación histórica en un periodo determinado. ${ }^{1}$ Bajo tal premisa, se arroja la hipótesis que señala

${ }^{1}$ Foucault, Arqueología, 2001, pp. 227-235. el más remoto posicionamiento historiográfico realizado en Nuevo León presentado de una forma general e íntegra, el cual se encontraría a partir de la segunda mitad del siglo XIX. Y si bien la investigación histórica y la producción historiográfica continúan hasta ahora, se propone el corte en torno a los festejos de los 400 años de Monterrey y el impacto que esto tuvo respecto a rescatar y presentar una obra historiográfica. Lo anterior implica advertir la elaboración y circulación de un conocimiento bistórico que, siguiendo a Gadamer, es la representación de una singularidad, de una experiencia particular de un pueblo, de una cultura, de una región. ${ }^{2}$ Así, concebida la idea, el artículo se centratá en desarrollar y explicar un par de aspectos: detectar y exponer brevemente el planteamiento de las etapas que aquí se proponen y se presentan de la historiografía regional en Nuevo León, así como la incidencia que en ello ha tenido el respectivo ámbito institucional del oficio.

\section{HISTORIOGRAFÍ Y REGIÓN HISTÓRICA: EL CASO DEL NORESTE MEXICANO}

La historia económica reciente señala como hito transformador del noreste la redefini-

\footnotetext{
${ }^{2}$ Gadamer, Verdad, 2001, pp. 32-33.
} 
ción de la frontera norte de México, que fue resultado de la guerra contra Estados Unidos entre 1846 y $1847 .{ }^{3}$ Dicha circunstancia desencadenaría un proceso comercial y económico y provocaría un reordenamiento del espacio regional alrededor del bajo río Bravo, es decir, se consagraría en las décadas posteriores al episodio bélico, un entorno regional-binacional que se extenderá más allá de las fronteras propiamente nacionales de ambos países. De tal forma, Coahuila, Nuevo León y Tamaulipas, en el gran norte oriental mexicano, y Texas, como parte de Estados Unidos, se articularán bajo una dinámica geoeconómica que propiciará condiciones políticas, económicas e históricas únicas no sólo respecto al resto de México, sino incluso a Latinoamérica.

Tales circunstancias originarán un inédito desarrollo de la ciudad de Monterrey. Fundada en 1596, y al ser un punto perdido durante varios siglos en la vasta geografía de Nueva España, "La Sultana del Norte" se revitalizará con la cercanía de la nueva frontera, como les sucederá a otras ciudades y puertos en el entorno noreste. Como lo ha presentado la historia económica al estudiar el pasado mediato de la región, el contacto que tuvo el noreste mexicano con el capitalismo autónomo que se gestó en Estados Unidos impactaría a la zona ubicada al sur del río Bravo. Luego de la invasión estadunidense y el acercamiento de la frontera norte, se presentó

${ }^{3}$ Vizcaya, Origenes, 2001, p. xIv; Cenutti, Burgutesia, 1992, p. 31, y Herrera, Zona, 2004, pp. 77-115. Si bien es Mario Cerutti quien en las últimas décadas ha profundizado en estas premisas, un autor como Isidro Vizcaya desde los años sesenta ya planteaba tales inferencias en el estudio del desarrollo económico y de la dinámica comercial en torno al bajo río Bravo. otra vicisitud que favorecería el comercio e intercambio económico en el noreste: la guerra de Secesión en Estados Unidos entre 1861 y 1865.

Las condiciones para el "tráfico ilícito" de mercancías y el estímulo provocado por la guerra intestina en esa parte continental incidirían en la acumulación de las fortunas de familias que aún hoy guardan poder e influencia. Muchas de ellas decidirán radicar en Monterrey y, al paso de las décadas, se convertirán en una respetable elite económica nacional que impulsará la creación de poderosos emporios industriales. ${ }^{4}$ Circunstancias tales como la concentración del poder político y militar de Nuevo León en la ciudad de Monterrey y los recursos naturales como agua, tierra propicia para la agricultura, así como la ganadería en un valle con ríos, arroyos y ojos de agua cercanos, los harán decidir radicar en la capital nuevoleonesa. ${ }^{5}$ Asimismo, los negocios y tratos que tenían dichas familias con el gobierno del estado -cuyo erario casi siempre estaba en condiciones de precariedad-, como el concerniente a brindar financiamiento con altos rendimientos en la guerra de exterminio contra las tribus nómadas, constituyó una razón más para establecerse en la capital de Nuevo León. En resumen, y apelando a los resultados de investigación que la historia económica ha hecho sobre la región,

${ }^{4}$ Saragoza, Monterrey, 1988, pp. 16-71.

${ }^{5}$ Vizcaya, Orígenes, 2001, pp. XI-XIII. El autor retoma invaluables testimonios y memorias de personas (J. Kenley, M. Rankin, A. Santleben, F. A. Ober) que vivieron o estuvieron durante aquella época en Monterrey o en el noreste. Fue el caso de aquellos que se encontraban en la entonces pequeña población huyendo de la guerra de Secesión o de soldados estadunidenses que, formando parte de las tropas, recorrieron la región a pie durante la invasión a México. 
se puede explicar cómo Monterrey logró despuntar de entre el sistema de ciudades que se articuló en el noreste y atraer a una burguesía que impulsará un desartollo singular respecto a la experiencia nacional y latinoamericana.

La relación entre puntos fronterizos, puertos en el Golfo y ciudades en la parte continental desarrollada en la segunda mitad del siglo XIX propició un entorno con una cultura, con un modo de vida y con aspiraciones propias que se manifestarán en actividades como la música, la literatura, la gastronomía, la arquitectura o la historiografía. Esta última, entendida como memoria bistórica de la región, es lo que reclama nuestra atención. Así, parte del corpus historiográfico de Nuevo León -por lo menos el que se ha estudiado, escrito y publicado desde la década de 1960- hace alusión a la evolución del estado y particularmente al de la ciudad de Monterrey, señalando vicisitudes y circunstancias que ocurrieron más allá de su límite geográfico.

De igual forma, cabe advertir que desde la época de la colonización en la región aparecieron algunos factores que determinaton su devenir. Entre ellos es posible mencionar la lejanía respecto a la ciudad de México -centro político nacional-, librar la llamada guerra viva -expulsión del "bárbaro" de sus solares y su posterior exterminio- emprendida contra las naciones indígenas nómadas en el norte, así como la precariedad de las vías de comunicación que volvía muy difícil el contacto entre los distintos territorios y regiones del país, lo que provocó, y quizá obligó, a que sus moradores buscaran a toda costa su supervivencia por medios propios. Se propició una forma de colonización en cierto modo distinta a la desarrollada en el centro, sur y sureste del país.
De esta forma, es posible partir de la premisa que apunta hacia una conformación sociohistórica del noreste de acuerdo con las condiciones propias de un proceso civilizatorio, según lo expone Elias. Dicho proceso se remitiría a la parte del septentrión fronterizo de México situada en el bajo río Bravo, el cual representa un cúmulo de experiencias (históricas, culturales, étnicas, geográficas, políticas, económicas) que se han gestado y practicado durante un periodo extenso. ${ }^{6}$ Un trabajo de investigación que desarrolla esta tesis es el de José Cuello, quien presenta una lectura acerca de la experiencia colonial en la región -en este caso desde Saltilloen cuya etapa se encuentra el origen histórico del regionalismo del noreste. ${ }^{7}$

Ya en un periodo posterior, la elite económica regiomontana tendrá que hacer frente a la inestabilidad política en el país a fines del siglo XIX y primeras décadas del Xx; de la pax porfiriana hasta la llegada de la revolución, y de esta a la consagración del Estado mexicano posrevolucionario, la burguesía local debió hacer frente a los proyectos dictados por el poder central en lo político y económico particularmente. Es importante hacer notar que investigadores estadunidenses han abordado el tema, donde exponen las condiciones económicas, políticas y militares alrededor del bajo río Bravo que detonaron la actividad mercantil y comercial del nuevo entorno. ${ }^{8}$ Situaciones acaecidas a partir

${ }^{6}$ Elias, Proceso, 1994 , pp. 9-46.

${ }^{7}$ Cuello, Norte, 1990, pp. 171-186.

${ }^{8}$ Cerutti y González, Frontera, 1993. Dicha compilación presenta aportaciones importantes de la historiografía del sur de Estados Unidos - particularmente texana- producida entre las décadas de 1920 y 1970 , cuyo objetivo fue el estudio de un "espacio binacional" 
de la década de 1860 -como aquellas que corresponden a los vínculos políticos, militares y económicos entre Texas y las entidades mexicanas del noreste a partir de las luchas intestinas de cada país- rebasaron los límites geográficos de ambas naciones. Se trataría, según concluyen estos estudios, de un ámbito histórico regional.

Si bien los procesos de autoorganización en términos políticos, militares y económicos durante buena parte del siglo XIX fueron una constante en México -casos como la notoria influencia de Pesqueira en Sonora o la hegemonía de Vidaurri en el noreste que abarcaba desde Monterrey son elocuentes-, ante la imposibilidad de concretar un poder central fuerte, la situación del noreste $-y$ particularmente la que correspondió a la capital nuevoleonesaserá una situación histórica única al ser impactadas por el floreciente capitalismo autónomo que se gestaba en Estados Unidos.

Varios son los autores que, bajo distintos perfiles y particulares preocupaciones, han hecho aproximaciones para definir el concepto que aludiría a la zona noreste. A partir de las consideraciones más recientes sobre dicha noción, se pretende conceptuar en el presente artículo a este espacio como un entorno regionalbinacional que ha compartido y comparte una relación histórica, geográfica, política, económica, social y cultural; se trata de un gran ámbito que comprende las actua-

y la articulación de una "economía de frontera". Los trabajos son breves artículos provenientes de tesis tanto de maestría como de doctorado realizadas en universidades estadunidenses, así como de títulos publicados de Ann Cowling, Frank L. Owsley, Williarn Diamond, Le Roy P. Graf, R. T. Delaney, J. Irby, R. C. Tyler y A. Mayer. les entidades de Coahuila de Zaragoza, Nuevo León y Tamaulipas en México, así como buena parte de Texas en el sur de Estados Unidos.

Roberto García Ortega, urbanista e investigador del Colegio de la Frontera Norte en Monterrey, en sus estudios sobre planeación y gestión urbana detecta una serie de corredores que entrelazan algunos puntos de las entidades de Coahuila, Nuevo León, Tamaulipas y Texas. Tanto MonterreyTampico y Monterrey-Cuenca Carbonífera-Piedras Negras-Eagle Pass como Monterrey-Saltillo, Monterrey-Miguel Alemán y Monterrey-Reynosa-Matamoros-Brownsville son señalados como puntos estratégicos de un espacio funcional industrial que tendrá en el área metropolitana de Monterrey su punto nodal. En este sentido, García Ortega considera a los municipios de Apodaca, Escobedo, García, Guadalupe, Juárez, San Nicolás, San Pedro y Santa Catarina como parte de la zona urbana alrededor de la capital del estado. ' Según Cerutti, una premisa ligada a la anterior, la cual refiere a la composición de un sistema de ciudades y a la dinámica comercial y económica que propició, propone detectar su origen a mediados del siglo XIX. Así, este historiador adscrito a la Universidad Autónoma de Nuevo León que ha estudiado la genealogía de la burguesía regiomontana y el desarrollo económico $\mathrm{e}$ industrial de Monterrey, sugiere que el episodio que propiciaría nuevas condiciones para la región del bajo río Bravo fue la invasión y guerra con Estados Unidos. A partir de tan drástica circunstancia, se reordenó buena parte del territorio colindante en ambas márgenes de la nueva frontera y con el Golfo de México, hasta

${ }^{9}$ García, Monterrey, 2003, pp. 53-62. 
conformar un espacio geográfico con un desenvolvimiento económico propio y una organización político-militar con cierta autonomía. Para hacer referencia a esto, el historiador acuña el término gran norte oriental. ${ }^{10} \mathrm{Si}$ bien tal conceptualización expuesta desde la historia económica abarca porciones de las actuales entidades de San Luis Potosí, Zacatecas, Durango y Chihuahua -incluso Nuevo México más allá de la frontera nacional-, su propuesta se concentra en la vasta región que comprende Coahuila, Nuevo León, Tamaulipas y Texas. Asimismo, Manuel Ceballos Ramírez, historiador e investigador del Colegio de la Frontera Norte en Nuevo Laredo, ofrece otra visión de la conformación sociobistórica de la frontera. Coincide con Cerutti en detectar el origen más remoto en las consecuencias políticas y jurídicas de la guerra contra Estados Unidos, pero la enriquece al contemplar aspectos culturales (mitos, leyendas), étnicos (anglos, hispanos, mexicanos, indígenas) e históricos (reconocimiento de "autonomía" e "independencia") en constante interacción que vuelven compleja la delimitación geográfica tradicional de la zona. ${ }^{11}$ Así, su concepción de noreste bistórico mexicano responde no sólo a aspectos de dinámica comercial, flujos productivos e intercambio económico, sino que rescata el carácter social, histórico, cultural y geográfico implícito en la colindancia territorial de dicho espacio.

Con el desarrollo industrial y el progreso material de Monterrey a fines del siglo XIX, de forma más o menos acelerada, la ciudad acaparó muchas de las fun-

${ }^{10}$ Cerutti, Burguesía, 1992, pp. 31, 115 y ss.

${ }^{11}$ Ceballos, Cuatro, 1999, pp. 9-21, y "Consideraciones", 2003, pp. 71-87. ciones políticas, económicas, financieras, culturales, educativas y académicas que englobaban a todo el estado de Nuevo León. De hecho, en cuestión demográfica, a partir de 1970 empieza a concentrarse la población en torno a la capital política de la entidad hasta constituirse un área metropolitana. ${ }^{12}$ Como ya se expresó, la intención aquí es advertir que, en múltiples sentidos, cuando se habla de Monterrey se hace referencia a Nuevo León. Incluso al noreste.

A partir de tal premisa se pretende investigar el origen y desarrollo del quehacer historiográfico en Nuevo León justo en el momento cuando su capital, Monterrey, primero logra una dinámica económica, la cual después detonará un inédito proceso industrial. Esa situación que experimentó la ciudad será un fenómeno que reclamará la atención de cronistas, sociólogos, economistas e historiadores. Las aportaciones hechas por autores de distintos perfiles, en diferentes épocas y guiados por particulares preocupaciones, se han acumulado en un número importante de obras (folletería, mimeos, revistas, compilaciones, libros y tesis) que ha logrado consagrar un tipo de conocimiento sobre el pasado de Monterrey, de Nuevo León y del ámbito regional donde están inmersas tanto la ciudad como la entidad.

Por lo tanto, y desde una primera aproximación, es posible detectar dos aspectos en la historia mediata del noreste mexicano y en el corpus de la historiogra-

${ }^{12}$ García, Monterrey, 2003, pp. 53-62. Según lo expone el autor, en el año 2000 los habitantes ubicados en el área metropolitana de Monterrey sumaban 3237000 personas, mientras que el dato del INEGI para el mismo año, apuntaba una población en el estado de 3834141 habitantes. 
fía nuevoleonesa: a) cuando se habla de la historia de Nuevo León es necesario hacer mención de procesos tanto históricos, políticos y culturales como económicos y militares que se circunscriben a un dilatado escenario territorial que se extiende en ambas márgenes de la frontera norte, los cuales ocurren desde la propia colonización; $\mathrm{y} b$ ) el quehacer historiográfico en Nuevo León -por lo menos lo más granado donde se plasma la reconstrucción de ese pasado histórico mediato- ha encontrado su punto principal de producción y difusión en un solo lugar, en este caso Monterrey, por ser el pivote del estado y de la mencionada región.

Lo que a continuación se presenta es una breve y concisa reflexión acerca de cuáles condiciones académicas e intelectuales han propiciado su surgimiento, bajo qué entorno institucional ha tenido su desarrollo, cómo se han organizado autores e instituciones para dar vida a una operación bistoriográfica como esta, qué posturas y propuestas metodológicas se encontrarían en dicha operación, qué tipo de personajes se han involucrado en dicha actividad y qué posibilidades de orientación guarda.

\section{PRIMERAS APORTACIONES \\ DE LA hISTORJografía EN NUEVO LEÓN}

Las aportaciones pioneras del quehacer historiográfico en el noreste son detectadas por algunos autores a partir del lejano proceso de colonización en el extenso norte. En la década de 1970, Israel Cavazos señalaba tres: Alonso de León con su Relación y discursos del descubrimiento, población y pacificación del Nuevo Reino de León; temperamento y calidad de la tierra; Juan Bautista Chapa y su Historia del Nuevo Reino de León de 1650 a 1690; así como Descubrimiento de Río Blanco y conversión de los naturales, becha por los religiosos de nuestro seráfico padre san Francisco de Fernando Sánchez de Zamora. Y vale la pena agregar la Descripción de Nuevo León (1735-1740) realizada por Josseph Antonio Fernández Jáuregui Urrutia. Dichas obras corresponden al siglo XVII y destacan las necesidades, así como las condiciones de la época colonial de la zona (supervivencia en un escenario regional, lejanía del centro político nacional, lucha contra las naciones indígenas). ${ }^{13}$

Otra referencia al respecto la hace Francisco Ruiz Solís, quien en un artículo cita el impacto que produjo el Real y Tridentino Colegio Seminario de Monterrey (1791) en la actividad cultural e intelectual del Nuevo Reino de León. Dicha institución generó diversas actividades de tipo intelectual, como la elaboración de memorias, registros y constancias del acontecer de la época. También inició los primeros y loables esfuerzos en cuanto a atender y promover la instrucción durante una etapa especialmente precaria y difícil para una empresa como esta. ${ }^{14}$

Por otra parte, Héctor González hace un señalamiento acerca de las ediciones y publicaciones locales al referirse a las primeras imprentas. ${ }^{15}$ Ligado a lo anterior,

${ }^{13}$ Cavazos, Estado, 1976, pp. 882-886.

${ }^{14}$ Ruiz, "Apuntes", 1992, p. 163.

15 González, Siglo, 1946, pp. 31-35. Según se desprende de su obra, es en agosto de 1813 cuando llega la primera imprenta a Monterrey traída por Joaquín de Arredondo, brigadier español que se encontraba en combate ante tebeldes insurgentes. Pocos servicios pudo prestar, y hasta abril de 1817 llegó otra de Inglaterra por Francisco Javier Mina y fray Servando Teresa de Mier; acompañada por el impresor estadunidense Samuel Bangs, pionero del oficio en la región. Dicha imprenta brindó servicio a las lla- 
Rafael Garza Cantú realizó una extensa investigación sobre las letras y la cultura nuevoleonesa, en donde otorga un espacio importante al primer periódico editado en el estado. Se trata de La Gaceta Constitucional de Nuevo León, publicación oficial con pretensión de difundir el "derecho público" y exponer la "verdad histórica y visión social de la época". ${ }^{16}$

En tales condiciones de efervescencia política y lucha ideológica, de igual trascendencia resulta la Revista de Nuevo León y Coabuila editada y publicada por Manuel García Rejón, político e intelectual avecindado en la región y allegado a Santiago Vidaurri. García Rejón se da a la tarea de presentar el pasado regional a partir de la consulta y publicación de documentos históricos contemplados como "fuente de verdad". Este será uno de los primeros esfuerzos de una historia regional que respondía a los intereses políticos del momento, aquellos que apelaban a una independencia y autonomía de Nuevo León y su entorno geográfico inmediato.

Estas expresiones intelectuales y culturales -las últimas inspiradas en llevar a cabo una tarea política y un posicionamiento ideológico- responden a una coyuntura y preocupación histórica y social de la época. Se trató de una etapa en la cual México -luego de sufrir guerras intestinas y hacer frente a invasiones- se encontraba en el momento más crucial de su historia. Así, el dilema podría presentarse de la siguiente manera: fragmentarse en

madas Provincias Internas de Oriente, que comprendía los estados de Texas, Coahuila, Nuevo León y Tamaulipas. Otras dos imprentas arribaron en 1823 y 1824; la primera a cargo del municipio de Monterrey y la última por el gobierno del estado.

${ }^{16}$ Garza, Algunos, 1995, pp. 172-185. regiones que estaban obligadas a autoorganizarse -que de hecho lo hacían, como el noreste- o replantear la composición de un Estado nacional fuerte. En tales condiciones, la historiografía del siglo XIX, como otras actividades intelectuales, fue tomada como instrumento para encarar una de las problemáticas que debían resolverse: elaborar una conciencia nacional ante las circunstancias que amenazaban el proyecto de país. De manera aparentemente paradójica, dichas experiencias regionales habían sido las que inspiraron a periodistas, abogados, médicos, sacerdotes, militares, literatos, entre otros, para llevar a cabo los más anticipados ejercicios para investigar y escribir la historia de sus respectivos lugares. Muchas de esas versiones que rescatan el pasado regional en México todavía siguen sin ser valoradas en su justa dimensión. Vamos, algunos ni siquiera las reconocen como obras de historia y mucho menos consideran que pueda plantearse a partir de ellas una situación digna de ser estudiada. Pese a ese estrecho criterio de algunos, se pretende mostrar que las obras cuyo cúmulo compone un rico y variado corpus historiográfico han tenido en su momento una aportación e impacto en lo político, en lo intelectual, en lo cultural y en lo académico en sus respectivos ámbitos desde donde se han difundido. Es en este sentido que una publicación puede convertirse tanto en fuente como en objeto de estudio.

\section{APORTACIONES RECIENTES AL ESTUDIO DE LA HISTORIOGRAFÍA EN NUEVO LEÓN}

Israel Cavazos Garza (n. 1923), historiador egresado de El Colegio de México (COLMEX) y cronista de Monterrey desde 1992 
tras el deceso de José Pedro Saldaña, escribe para la Enciclopedia de México un apartado sobre Nuevo León, t. IX, en donde presenta un breve listado de las obras y autores que conforman el corpus historiográfico regional. La edición aquí consultada es de un "sobretiro especial" por encargo del Ayuntamiento de Monterrey en 1976 que lleva por título Estado de Nuevo León y ciudad de Monterrey, donde se describe, entre otras cosas, la actividad historiográfica desde las crónicas coloniales del lejano siglo XVII hasta la obra escrita y publicada a principios de los años setenta del siglo $\mathrm{XX}$. De interés para el presente trabajo es el señalamiento que Cavazos hace de autores pioneros en la última parte del siglo XIX y principios del $\mathrm{xX}$, así como exponer de forma breve las condiciones históricas de esas etapas.

Por su parte, el sociólogo Francisco Ruiz Solís (n. 1957) escribe un apartado acerca de la actividad intelectual y científica en el título Desde el Cerro de la Silla. Artes y letras de Nuevo León editado por Miguel Covarrubias en 1992. Con "Apuntes para la historia del pensamiento científico de Nuevo León", el autor poblano contempla dicho pensamiento como parte de una actividad y producción intelectual más amplia generada desde la época colonial. En especial, centra su atención en cronistas, escritores, periodistas, educadores, prominentes intelectuales que han hecho aportaciones al incipiente conocimiento en la entidad, siempre desarrollado desde Monterrey. Tras considerar el entorno propiciado en principio por el ya mencionado Colegio Seminario de Monterrey, su recorrido lo lleva hasta lo realizado en la década de 1980 durante el cual expone las condiciones que han tenido que ver con la vital y pujante institucionalidad de un ámbito propiamente académico en la capital nuevoleonesa. Así, y en lo referente a los estudios sobre historia regional, presenta lo realizado en el tema por autores ubicados en distintas etapas desde el doctor González hasta Cerutti.

Otra contribución en este sentido es la propuesta de Manuel Ceballos Ramírez (n. 1947), quien presenta Historiografía nuevoleonesa publicada por el Archivo General del Estado de Nuevo León (AGENL) en 1995. El interés del autor es esbozar la creación historiográfica en la entidad desde la década de 1930 hasta los años noventa y detectar algunas circunstancias que propiciaron tal actividad. Al mencionar a cronistas e historiadores - de Cossío a Vizcaya y de Roel a Cerutti-, así como la incidencia de las instituciones (universidades, asociaciones, bibliotecas y acervos), Ceballos es quien mejor se ha aproximado al estudio del oficio de historiar y al quehacer historiográfico durante gran parte del siglo Xx. A diferencia de los otros autores citados, se ocupa de detallar aspectos y condiciones que han influido en la historiografía de Nuevo León, con lo que logra detectar aportaciones que han marcado la consumación en algún grado de ciertas expectativas. Ese es el caso de "historia" e "identidad" en la propuesta de Rangel Frías.

La más reciente propuesta escrita sobre el tema la hace César Morado (n. 1969), filósofo e historiador egresado de la Universidad Autónoma de Nuevo León (UANL). Este autor presenta un pequeño artículo en la revista saltillense Provincias Internas publicada por el Centro Cultural Vito Alessio Robles en 2001, en el cual realiza un recuento de la actividad historiográfica hecha en Monterrey desde 1980. En "Historia de Nuevo León. Apuntes epistemológicos para una historiografía recien- 
te", el autor detecta cuatro tendencias desarrolladas en los últimos 20 años: historia e identidad, historia económica, historia de género y la bistoria de las mentalidades. Según la propuesta de Morado, las primeras dos han logrado consolidarse mediante la producción de un corpus importante con aportaciones como las de Raúl Rangel Frías e Israel Cavazos (historia e identidad) o de Isidro Vizcaya y Mario Cerutti (historia económica); esta última, sin duda, es la que más se ha revitalizado con la puesta en marcha de la licenciatura en historia en la UANL. Por lo que toca a la historia de género y aquella inspirada en la propuesta de las mentalidades, existen investigaciones sobre las situaciones de las mujeres tanto en lo urbano como en lo rural (Veronika Sieglin), así como intentos bajo las nuevas posturas conceptuales y metodológicas de la escuela francesa -en especial basados en autores como Michel de Certeau-, lo cual implica esfuerzos por encontrar nuevas vetas y empezar la orientación hacia otras tendencias en la historiografía reciente en Nuevo León.

Como se ha tratado de explicar, la producción historiográfica del estado tiene sus bases tanto teóricas (metodología, conceptualización, tendencias, posicionamiento ideológico) como institucionales (creación de agrupaciones, institutos, universidades $\mathrm{y}$ asociaciones), que han delineado la forma en que se ha investigado y escrito sobre el pasado de la entidad y la región.

Se han presentado brevemente algunos de los elementos, así como señalado ciertas condiciones que han incidido en la forma y tendencia del corpus historiográfico tegional. Como se ha expuesto, esto representa una forma de conocimiento bistórico que ha logrado un desarrollo trascendente que reclama debatir su origen, el pro- ceso que lo ha acompañado, las condiciones que lo han propiciado y qué orientaciones y tendencias ha tomado. En general, se puede concluir de forma anticipada que toda historiografía, así como el conocimiento sobre el pasado que eso implica, se encuentra sujeta tanto a condiciones sociales, políticas, culturales y económicas como a las reglas que regulan el oficio desde el punto de vista institucional según la época. A partir de esta idea se desarrolla la siguiente propuesta.

\section{LA PRÁCIICA HUSTORIOGRÁFICA EN NUEVO LEON: ETAPAS, CONDICIONES, OBRAS Y AUTORES}

El espacio temporal (1867-1996) al que aquí se alude para el estudio de la historiografía regional es extenso. Por ello, para un mejor análisis y estudio propongo fraccionar dicho espacio en cuatro periodos según posturas intelectuales de los autores, tendencias académicas y condiciones institucionales en torno al quehacer historiográfico nuevoleonés: prolegómenos (1867-1925), regionalismo (1925-1942), institucionalización (1942-1974) y profesionalización (1974-1996). La idea es partir de estos $t i$ pos ideales, según lo planteara Weber, para someterlos a prueba y darnos cuenta de qué tan útil y acertada puede ser esta aproximación. A continuación analizo la caracterización en cada uno de los espacios temporales.

Primer periodo: prolegómenos (1867-1925)

En 1867 aparece la obra Colección de noticias y documentos para la bistoria del estado de Nuevo León, escrita por el médico, político 
e intelectual José Eleuterio González (1813-1888). Si bien para entonces ya existía producción historiográfica, como se ha mostrado, que pretendía reconstruir el pasado del estado y de la región, esta obra representa el primer intento integral respecto a una visión histórica de la entidad. Prueba de esto fue la consideración de aspectos geográficos, cronológicos y estadísticos para, a partir de la búsqueda y transcripción de documentos, desarrollar esa operación historiográfica. Pero las fuentes consideradas por el autor no se limitaban a lo anterior, ya que para el historiador tenían igual importancia las crónicas o los diarios de la época colonial escritos por conquistadores o sacerdotes.

Tapatío avecindado en Monterrey desde los 20 años de edad, el doctor González es el prototipo del escritor decimonónico, ya que su labor abarcó rubros que ahora pudieran ser vistos como ajenos y lejanos entre sí, como la medicina y sus distintas ramas, la política o la historia. Según Luis González, dicho personaje pertenecería a la destacada generación de la pléyade de la reforma, cuyas figuras nacionales, como Prieto, Barreda, Payno o Iglesias, fueron piezas clave para el proceso intelectual y político de México. ${ }^{17}$

Pese a que comenzaba a configurarse en el país un escenario donde la pauta era marcada por el posicionamiento positivista para investigar el acontecer humano en general y ofrecer una explicación "efectiva", "racional" y "sistemática", siempre con base en el trabajo empírico, los estudios de historia basados en dicha propuesta científica aparecerán durante la última parte del porfiriato. En tal sentido, José Eleuterio González realiza una propuesta

${ }^{17}$ González, Ronda, 1997, pp. 17-32. historiográfica que se apegara más a un romanticismo con profunda preocupación y compromiso social; es decir, sí se rescataba la experiencia histórica regional mediante la búsqueda, entre otras fuentes, de documentos, pero se escribía según el canon literario de la época, próximo al estilo neoclásico. Como lo señalara alguna vez Matute, el hecho de reconstruir el pasado mediante documentos no implica que se trate de una historia de cariz positivista. En todo caso, fueron otras disciplinas las que de manera anticipada adoptaron el positivismo para realizar sus trabajos, estudios e investigaciones. ${ }^{18}$

Para el último cuarto del siglo XIX aproximadamente, mientras la situación del país tendía a estabilizarse y era posible realizar los primeros intentos por consolidar un Estado nacional fuerte, la historiografía que entonces empieza a practicarse posee un marcado carácter político y la preocupación de consagrar una conciencia nacional. ${ }^{19}$ Sin embargo, la producción historiográfica regional ofrecía una mirada de lo ocurrido en ciertas zonas del país; novelas históricas, crónicas, trabajos biográficos, libros de texto, etc., formaban parte de un corpus historiográfico que se enriqueció durante las décadas que unen

${ }^{18}$ Matute, "Notas", 1991, pp. 49-64. Matute señala en este artículo que fue en el campo de la medicina donde aparece por vez primera un planteamiento metodológico propiamente positivista, como fue el caso de la Historia de la medicina en México (1888) de Francisco de Asís Flores. Por lo que respecta a los estudios sobre historia, será hasta la última parte del porfiriato cuando se realicen dichos ejercicios como el que corresponde a México: su evolución social 19001902 , cuya pléyade de autores fue encabezada por Justo Sierra.

${ }^{19}$ Pi-Suñer, "Generación", 1996, pp. 83-108. 
a los siglos $\mathrm{xrx}$ y $\mathrm{xx} .{ }^{20}$ Precisamente el hecho de que tal cúmulo de obras de historia estatales escritas y publicadas haya aparecido durante este tiempo da cuenta de que la idea de "lo nacional" se representaba desde el rescate y valoración de las experiencias locales y regionales. La conciencia nacional no era algo propio de las historias generales que entonces se escribían desde la capital.

En el caso de Nuevo León, y por lo que concierne al citado escritor, dicha labor la desarrolló en condiciones de un ámbito institucional específico en torno al Colegio Civil -fundado por decreto gubernamental de la entidad en 1857 , pero que iniciaría sus funciones a fines de 1859y/o del propio gobierno del estado. Se trató, según Certeau, de ese lugar de producción que volvía posible y legítima dicha actividad intelectual, es decir, ambas instituciones fungieron como los márgenes de su ejercicio "escriturístico". ${ }^{21}$

Entre el grupo de intelectuales que hicieron aportaciones a la historiografía de la entidad en este periodo cabe mencionar, además del propio doctor González, al abogado y discípulo de dicho doctor en el Colegio Civil, Hermenegildo Dávila (Catecismo bistórico, geográfico y político de Nuevo León, 1881; Cartilla histórica de Nuevo León, 1897), Genaro García (Historia de Nuevo León, con noticias sobre Coabuila, Tejas y Nuevo México, 1906), Rafael Garza Cantú (Algunos apuntes acerca de las letras y la cultura en Nuevo León, en la centuria de $1810-$ 1910, 1910) y Amado Hernández (Ono-

${ }^{20}$ Arias, "Dimensión", 2005. En esta tesis doctoral la autora demuestra el auge que tuvo la investigación y publicación de las historias regionales en México en el transcurso de los años 1890 y 1915.

${ }^{21}$ Certeau, Escritura, 1993, p. 69. matografía del estado de Nuevo León, 1918), entre otros.

Todos ellos estuvieron resueltos a construir desde su región -según la individualidad bistórica en la que estaban inmersos y tomando a la historiografía como instrumento- una memoria bistórica, sin perder de vista a la cultura nacional de la cual formaban parte. Asimismo, y durante la última parte de esta etapa, una característica del corpus historiográfico fue la concepción organicista como tendencia del positivismo (Dávila, Garza Cantú), a partir de la cual los autores recreaban el pasado de la entidad. Si bien la intención era rescatar las vicisitudes y sucesos regionales, las obras hacen énfasis en que Nuevo León forma parte de una realidad más amplia y general que es México. Pero, insisto, esto no implicó la intención de considerar la experiencia histórica regional como la de una "patria chica", sino que dicha experiencia es la de una realidad nacional concreta en un lugar específico. Además, un anhelo y preocupación que dejan ver estos autores era la idea de contribuir con su quehacer a la formación de ciudadanos, ya que estaban convencidos de que una nación que aspiraba a la modernidad y al progreso necesitaba propiciar y promover como fuera posible la instrucción de sus habitantes (Dávila). La intención era educar a la población para formar ciudadanos, lo cual resultaba requisito para un país que pretendía ser civilizado. Aquí empieza a dejarse sentir con bastante claridad el influjo de las ideas de autores como Comte y Spencer, y continúan considerando a otras disciplinas -política, geografía, estadística- en la escritura de la historia. Podría concluirse hasta este punto que la historiografía nuevoleonesa empieza a plasmar rasgos de la postura positivista 
ya en la última parte de esta primera eta$\mathrm{pa}$, en especial con las propuestas y posicionamientos de autores como Hermenegildo Dávila y Rafael Garza Cantú.

Por lo anterior, se considera que en aquel momento empiezan a realizarse los primeros esfuerzos por dotar a una actividad como la historia de reglas y campo propios. Consagrar a la historia como disciplina científica, sistemática y metódica resultaba, para los historiadores de la época, una pretensión que dejaban ver en sus obras.

Por último, es importante hacer notar que, entre quienes escribían la crónica e historia de entonces, se encontraban profesionistas con ocupaciones diversas; así, era común que abogados, periodistas, literatos o médicos realizaran esta tarea. De aquella generación de autores, es el doctor González el que marcó un hito en la historiografía regional de Nuevo León al tomar la llamada información oficial -en su calidad de intelectual ligado a la elite política y académica de entonces- disponible para realizar sus versiones, por lo que hasta ahora sigue siendo el más leído, citado, debatido y publicado.

Segundo periodo: regionalismo (1925-1942)

La aspiración de llevar a cabo la operación bistoriográfica de manera "objetiva", "imparcial" y "verdadera", así como mantener una preocupación por elaborar una memoria nacional, privaría en la historia escrita en la entidad hasta los años anteriores a 1930. En este sentido, Ruiz Solís estima que a partir de la segunda mitad de los años veinte habría empezado a gestarse una forma distinta de estudiar y escribir sobre el pasado, a la cual considera antipositi- vista. ${ }^{22}$ La premisa organicista que señala a la experiencia de Nuevo León como parte de lo acontecido en México, y este a su vez se encuentra dentro de un devenir histórico mundial, comenzaría, aparentemente, a ser abandonada por los más representativos historiadores locales. Sin embargo, como se mostrará, para dicha fecha todavía permanecen algunos rasgos que delatan ciertos resabios de aquel positivismo que varios autores tomaron para hacer los estudios de historia.

Como ya se mencionó, el positivismo como tendencia metodológica para realizar los estudios de historia llegó para asentarse debidamente como canon ya en los últimos momentos del primer periodo propuesto. En la década de 1940, Héctor González señalaba que ya había habido intentos por desmarcarse de dicha tradición metodológica que comenzaba a institucionalizarse para ir en búsqueda de nuevas vetas. Prueba de esto, argumenta el autor, fue la fundación de la Sociedad Científico-Literaria José Eleuterio González (1899) por parte de quienes entonces eran alumnos -además del propio Héctor González se encontraba otro personaje que destacó después, Santiago Roel- del Colegio Civil. ${ }^{23}$

En un sentido estricto esta nueva tendencia -intelectual en general y del ejercicio historiográfico regional en particular- se caracteriza por una revaloración del regionalismo posterior a la revolución mexicana con la intención de detectar y destacar una posible identidad particular de la zona. Es necesario advertir que para entonces ya se deja sentir el impacto que corresponde al desarrollo económico y al

\footnotetext{
${ }^{22}$ Ruiz, "Apuntes", 1992, pp. 170-171.

${ }^{23}$ González, Historia, 1945, pp. 27-29.
} 
primer auge industrial que experimentará la ciudad de Monterrey durante la bisagra de los años que entrelazaron a los siglos XIX y XX.

En esta etapa, resultan particularmente relevantes las aportaciones realizadas por tres personalidades de la esfera intelectual, cultural y académica de entonces. Se trata del escritor y poeta David Alberto Cossío y su Historia de Nuevo León. Evolución política y social, una monumental serie de seis tomos que se publicaron por veż primera entre los años 1925 y $1933 ;{ }^{24}$ del ingeniero Vito Alessio Robles con Monterrey en la bistoria y la leyenda, que apareció en 1936; y del abogado Santiago Roel Melo, quien presentaba en dos tomos la primera edición de Nuevo León. Apuntes bistóricos en 1938. Otra aportación para conocer de entonces corre a cargo de Miguel Martínez Rendón con Población de Nuevo León desde 1603 basta 1921 publicada en 1929. Los autores que dan vida a este corpus mantienen la noción de ir a la búsqueda de documentos y fuentes primarias para sustentar sus respectivas obras, quizá emulando al médico José Eleuterio González.

Pese a que Alessio Robles edita la citada obra en la ciudad de México, resulta una aportación importante para difundir no sólo la historia regional, sino también para promoverla en términos turísticos. Asimismo, hay que señalar que las versiones historiográficas de Cossío y Roel fueron consideradas como parte de la forma-

${ }^{24} \mathrm{Los}$ tomos I al Iv fueron publicados entre febrero y noviembre de 1925, el v en abril de 1926 y el vi vio la luz hasta febrero de 1933. Para 1927 Cossío presentaba un compendio adaptado de la obra para consulta de escuelas y colegios ubicados en el estado, el cual fue respaldado por el Consejo de Educación Pública estatal. ción -en distintos grados escolares durante un tiempo- de alumnos en la entidad; tanto Nuevo León. Apuntes históricos como Nuevo León. Evolución politica y social han sido empleadas como libros de texto por varias generaciones de nuevoleoneses para conocer la historia de su estado y de su región.

Así, se considera la aportación historiográfica de grandes miras realizada por Cossío como aquella que marca un nuevo rumbo, sólo preocupado por las condiciones históricas y sociales de la mencionada entidad, es decir, Nuevo León respecto a su ámbito geográfico inmediato, el noreste. Pese a los meritos de esta magna obra que, como aquí se propone, la pudieran distinguir de la producción realizada en la etapa anterior, su postura todavía guarda ciertos aspectos que hacen pensar en el positivismo organicista. Lo anterior es posible detectarlo desde el propio título que se utiliza al señalar la "evolución" que ha tenido la entidad. Esto sirve para dejar claro que los límites propuestos para cada periodo no resultan ser una camisa de fuerza, sino que están siendo planteados para ser abordados a manera de hipótesis.

Existen un par de acontecimientos que provocaron estas propuestas respecto a la lectura que se hacían entonces sobre el pasado: por un lado, el impacto que tuvo en esto el proceso de industrialización de Monterrey entre 1890 y 1910; por el otro, la irrupción de la lucha intestina entre 1910 y 1920 . El auge industrial y la dinámica económica en la ciudad, aunado a que en la guerra civil de principios del siglo $\mathrm{xx}$ la entidad tuvo una participación a lo mucho discreta, fueron condiciones que, en cierto modo, hacían ver a Monterrey y a Nuevo León como parte de una individualidad bistórica en el país. 
Aunado a dichos esfuerzos, comienzan a organizarse algunos jóvenes intelectuales del Colegio Civil inspirados en figuras prominentes del pensamiento mexicano de la primera mitad del siglo $\mathrm{Xx}$, como fue el caso del Grupo Alfonso Reyes. Entre los fundadores de esta agrupación se encontraba, entre otros, el entonces joven Raúl Rangel Frías, quien en las décadas posteriores reclamará su lugar como destacado intelectual e influyente político del estado.

En líneas generales, puede afirmarse que la historiografía realizada durante el periodo señalado fue resultado de la necesidad cultural, social y política para dotar al nuevoleonés de una identidad basada en los mediatos acontecimientos que dinamizaron a Monterrey, a Nuevo León y a la región.

También se mantiene la tendencia del periodo anterior respecto al perfil profesional de los autores de esta etapa, es decir, carecen de una formación académica como historiadores. Pero mientras autores como el doctor González o Dávila tuvieron en el estado o sus dependencias el respaldo institucional para hacer la operación historiográfica, en estos años aparecen nuevas posibilidades en ese sentido con imprentas y editores independientes. ${ }^{25}$

${ }^{25}$ Cossío, Historia, 1925, Prólogo. El propio Cossío en la presentación de la citada obra dice discrepar de la noción que el doctor González tuvo respecto a escribir historia, quien pensaba que para hacer dicha tarea era necesario estar respaldado por el Estado. Así, "conservar la independencia de criterio y el respeto a la verdad histórica" -planteaba Cossío anticipando a Certeau-eran posibles siempre y cuando el historiador se mantuviera al margen del Estado.
Tercer periodo: institucionalización (1942-1974)

Guillermo Zermeño alude que, ya avanzado el siglo XX, en la ciudad de México -centro político y cultural del país- se daban los primeros pasos dirigidos a profesionalizar el oficio de historiador. Así, instituciones como la Escuela Nacional de Antropología e Historia (ENAH, 1942) y la Universidad Nacional Autónoma de México, a través del Instituto de Historia (1945), marcaron la pauta en ese camino a la profesionalización. ${ }^{26}$

Siguiendo esta premisa y por la misma época, en Monterrey durante las décadas de 1930 y 1940 se fundaban instituciones que respaldarán y fomentarán el quehacer de diversas disciplinas. Sin duda, las más trascendentes son la entonces Universidad de Nuevo León que inicia varios de sus cursos en 1933 y la apertura del Instituto Tecnológico y de Estudios Superiores de Monterrey (ITESM) en 1943. Sin embargo, pasarán varios años para que ambas casas de estudio incidan de forma importante en la investigación y difusión sobre el conocimiento bistórico estatal y regional.

En tal sentido, se propone el comienzo de una nueva etapa en el quehacer historiográfico de Nuevo León con la fundación -interviniendo de manera decisiva Santiago Roel-, de la Sociedad Nuevoleonesa de Historia, Geografía y Estadística (SNHGE, 1942). Al aglutinar los esfuerzos de los interesados en temas históricos, geográficos, heráldicos, genealógicos y estadísticos se tomará a este intento como aquel que busca establecer un estatus institucional, reconocido y aceptado para realizar el

${ }^{26}$ Zermeño, Cultura, 2002, pp. 166 y ss. 
oficio de bistoriar en la entidad. De esta forma, la intención $-\mathrm{o}$ el reto- de tal acción era dotar a los estudios históricos de un fundamento científico, por lo que, como el nombre de la institución lo indica, habría que conjugarlo con las posibilidades que ofrecían otras disciplinas. Si bien desde tiempos del doctor González esto representó una tendencia y aspiración, ya entrado el siglo XX la historia en la entidad comenzaba a asumir su incipiente autonomía disciplinaria con la apertura de dicho organismo, cuya finalidad era fomentar y promover los estudios e investigaciones históricas en sus distintas vertientes. De esta forma, los márgenes institucionales comenzaban a tener nuevas opciones en un contexto inédito; ya no aparecen estos esfuerzos nada más como una propuesta del Estado, sino que las agrupaciones civiles ya se hacían presentes. ${ }^{27}$

En este periodo, como en los dos anteriores, cabe señalar a autores cuya preparación académica apunta hacia otras disciplinas, por lo cual sigue siendo común ver entre quienes escribieron la historia de Nuevo León a periodistas, abogados, médicos o ingenieros.

Pero aparece una situación de trascendencia: se advierte que a partir de entonces los interesados en la historia de la región comienzan a relacionarse de forma sistemática y periódica con otros prominentes historiadores mexicanos de entonces. Por supuesto que existió contacto y relación entre autores de las etapas anteriores con otros destacados personajes ubicados en distintas latitudes del país, como fue el

${ }^{27}$ Sin embargo, cabe mencionar que durante un tiempo la SNHGE recibía impulso y respaldo del Estado, si bien se trataba de una agrupación con carácter eminentemente civil. caso del doctor José Eleuterio González con el general y literato Vicente Riva Palacio, pero resultó ser esporádico, precario $y$ aislado ${ }^{28} \mathrm{~A}$ partir de este momento, quienes tenían la inclinación y el interés por los estudios históricos en Nuevo León empiezan a vincularse con notables historiadores mexicanos y extranjeros a partir de la organización del oficio en el ámbito local.

Así, se inician las primeras reuniones periódicas en Monterrey con el apoyo y reconocimiento de otras instituciones, además de contar con la asistencia y participación de conspicuos personajes. El caso de Daniel Cosío Villegas, descollante historiador y politôlogo mexicano, así como la presencia de instituciones que ya venían trabajando profesionalmente en la disciplina, nacionales como el Instituto Nacional de Antropología e Historia (INAH, 1939) y del extranjero como la American Historical Association (AHA, 1884), son muestra de las condiciones institucionales de la nueva etapa. ${ }^{29}$

Asimismo, hubo reacciones respecto a dichos esfuerzos organizativos. En 1947 se funda la Academia de Ciencias Histó-

28 Actualmente realizo una investigación acerca del doctor González y su quehacer como historiador. Entre otras cosas que he podido advertir es la conformación de un borizonte cultural en México durante buena parte del siglo XIX, en el cual los escritores de la época mediante sus trabajos lograron dar vida a un ámbito intelectual y políticamente activo. Entonces los individuos a través de sus obras se convertían en instituciones respecto a la construcción y circulación de un conocimiento bistórico.

${ }^{29}$ Ceballos, Historiadores, 1999. Esta edición facsimilar reproduce los textos presentados por los participantes de aquella primera ocasión, además de señalar las reuniones que han tenido historiadores mexicanos y estadunidenses a partir de 1949. 
ricas de Monterrey (ACHM), encabezada por el heraldista, genealogista e historiador regiomontano Carlos Pérez-Maldonado. Se trató de una respuesta a la ya constituida e integrada SNHGE y a su inclinación por implantar una práctica "objetiva y científica" de la historia. Para esto, dicha academia proponía como alternativa llevar a cabo una investigación histórica con visión e inspiración católicas. Pese a que resultó efímera, la ACHM tuvo el merito de promover y organizar las reuniones antes mencionadas entre historiadores mexicanos y estadunidenses -a las que recientemente se han incorporado canadienses como fue la de 2003 realizada en Monterrey-, llevándose a cabo la primera de ellas dos años después de fundado el citado organismo. Dichos encuentros se han realizado de manera periódica, teniendo en aquella primera ocasión como sedes a las ciudades de Monterrey y Saltillo, así como de contar con el patrocinio de poderosos emporios regiomontanos como la desaparecida Fundidora de Fierro y Acero de Monterrey.

La organización de los primeros seminarios, coloquios, conferencias y demás encuentros formales entre quienes se inclinaban por el estudio de la historia en la entidad representa una característica de este periodo que se conserva hasta nuestros días.

Entre los más destacados autores de dicha etapa se encuentran José Pedro Saldaña (Historia y tradiciones de Monterrey, 1943; Apuntes bistóricos sobre la industrialización de Monterrey, 1965), Héctor González (Siglo y medio de cultura nuevoleonesa, 1946), Raúl Rangel Frías (Teorema de Nuevo León, 1964), Eugenio del Hoyo (Historia del Nuevo Reino de León 1577-1723, 1972), Rodrigo Mendirichaga (Origenes de Nuevo
León, 1954); Antonio Morales Gómez (Cronología de Nuevo León, 1955), Andrés Montemayor (Historia de Monterrey, 1971), Nemesio García Naranjo (Una industria en marcha, 1955), Carlos Pérez-Maldonado (Narraciones bistóricas regiomontanas, 1959), Máximo de León Garza (Monterrey, un vistazo a sus entrañas, 1968), e Isidro Vizcaya Canales (Los orígenes de la industrialización de Monterrey. Una bistoria económica y social desde la caída del segundo imperio hasta el fin de la revolución [1867-1920], 1969).

Quizás Vizcaya sea quien en su obra logra imprimir un nuevo cariz en la práctica historiográfica, al superar la mera conjunción de datos teniendo la capacidad de relacionar sucesos de forma analítica y reflexiva. De hecho, considero a Vizcaya Canales -ingeniero agrónomo y topógrafo, maestro e investigador de historia en el ITESM prácticamente desde su fundacióncomo el autor que mayor influencia ha tenido en los historiadores de las siguientes generaciones respecto al oficio de bistoriar en Nuevo León. ${ }^{30}$ Asimismo, con esta propuesta logra marcar un nuevo paradigma en los estudios históricos sobre la región, tras ubicarla en un entorno espacial más amplio con lazos a través de lo comercial y económico. Pero no ubica este espacio limitándose a las cuatros entidades ya mencionadas -Coahuila, Nuevo León, Tamaulipas y 'Texas-, ya que amplía tal posibilidad al considerar entornos como el de Chihuahua e incluso Nuevo México. Insisto, el ingeniero convertido en historiador presenta esto en los años sesenta. Tal pro-

${ }^{30}$ Espinosa, "Poder", 2004, pp. 25-34, 111-120. Esta obra de Vizcaya ha sido reeditada en un par de ocasiones por la Librería Tecnológico, en 1971 y por el Archivo General del Estado de Nuevo Leốn en 2001. 
puesta vendrá a ser rematada al llegar la profesionalización del oficio en la entidad. Por lo anterior, muy bien podría considerarse a esta obra como la que marca la nueva forma de estudiar e investigar el pasado en la entidad, anticipándose varios años a lo que vendrán a realizar los historiadores profesionales.

De igual forma, la práctica que del oficio hacen otros autores como el ya citado Israel Cavazos Garza o Eugenio del Hoyo -ingeniero civil zacatecano avecindado en Monterrey- ya manifiesta ciertos rasgos que se anticipaban a la entonces no lejana profesionalización. Señalo dos de esos rasgos como lo fue circunscribir un objeto de estudio a partir de una delimitación temporal, así como especificar aspectos y problemáticas históricas concretas. Como se mostró, los historiadores de las dos etapas anteriores apostaron a la elaboración de las historias generales de sus entidades o regiones. Así, a partir de los años cincuenta la especialización será un nuevo cariz iniciado por tres historiadores quienes lo comienzan a delinear en sus investigaciones: Cavazos y del Hoyo abocados al estudio del pasado virreinal (conquista y colonización), mientras que Vizcaya hace lo propio respecto a algunos sucesos del siglo XIX (guerra viva, industrialización).

Por último, cabe mencionar las investigaciones y los estudios de autores extranjeros que ven en el contexto socioeconómico regiomontano de los años sesenta un caso sui generis, no sólo de México, sino de Latinoamérica. En un momento en que el país experimenta el llamado milagro mexicano, la capital nuevoleonesa reclama la atención de economistas, sociólogos e historiadores que busquen explicar ese desarrollo industrial y auge económico que la situaba como el ejemplo más elocuente e irrebatible de ese "milagro". Destacan en esta tendencia las aportaciones y los análisis realizados en aquella década por el francés Frédéric Mauro desde la historia (Le développement économique de Monterrey, $1890-1960,1964)$ y por el holandés Menno Vellinga desde la sociología (Industrialización, burguesía y clase obrera en México: el caso de Monterrey, 1979). ${ }^{31}$

Algo que se desprende de estas nuevas visiones y versiones es la articulación explícita de modelos teóricos y metodológicos para abordar no sólo el pasado de Monterrey, sino también la complejidad que ofrecía entonces. Tales publicaciones abrían una nueva veta que apuntaba hacia los trabajos sociohistóricos al considerar nuevas fuentes como la entrevista (Vellinga). Además, cuestiones como el ingreso, la movilidad laboral y la condición de la clase obrera -en ocasiones bajo la doxa marxista como lo llegó a manifestar Máximo de León- comienzan a ser atendidas por la historiografía local.

Podría decirse, otra vez de forma anticipada, que es durante estos años cuando empieza la práctica del oficio de bistoriar en Nuevo León de manera sistemática y organizada, y que la producción historiográfica es resultado de una nueva forma de considerar a la historia como una disciplina con reglas, procedimientos y ámbito propios de su quehacer. Pero esas reglas, procedimientos y ámbitos ya se volvían explícitos gracias, entre otras cosas, a que los interesados en estos temas se ha-

${ }^{31}$ Mauro, "Développement", 1964. En 1975 Mauro presenta su tesis doctoral en la Universidad de Florida, "Economic Development and the Dynamics of Class: the Case of Monterrey, Mexico". Dicha investigación será la base para desarrollar la obra citada. Vellinga, Industrialización, 1981. 
bían organizado. No es que antes no se tuvieran parámetros que delinearan y encauzaran su actividad en la entidad, ya que estos los tomaba de otras disciplinas -como fue el caso de la literatura en un principio-y esferas -creación de sociedades científicas- que se encontraban consolidadas y gozaban de un estatus intelectual y académico. Pero, a partir de entonces, quienes llevan a cabo la práctica de estudiar el pasado en Nuevo León habrán constituido un entorno intelectual propio y definido.

\section{Cuarto periodo: profesionalización (1974-1996)}

Si bien las instituciones académicas con mayor presencia en el estado tienen para entonces varias décadas de haber sido fundadas, hasta después de su apertura tuvieron incidencia en la investigación de la historia local y regional en la producción de un corpus historiográfico o en la formación de historiadores. En particular, es en 1974, en la Facultad de Filosofía y Letras (1950) de la ya UANL, ${ }^{32}$ cuando se inaugura el Colegio de Historia y se establece la licenciatura en Historia.

El modelo se tomó de la Universidad Nacional Autónoma de México (UNAM), lo que indica una relación de "centro-periferia" respecto al proceso de institucionalización de la disciplina en México. No se trata de un ejemplo aislado, ya que a partir de esa década se inicia una descentralización en cuanto a instituciones educativas de nivel superior y de posgrado, así

${ }^{32} \mathrm{La}$ Universidad de Nuevo León logra su autonomía el 5 de junio de 1971. como de centros de investigación. Bajo tal premisa, es posible detectar sistemáticos impulsos por llevar a otros puntos del país instituciones académicas y de investigación científica con la intención de acercarse, establecer, propiciar y fomentar el estudio de problemáticas locales o regionales, así como brindar diagnósticos sobre la multitud y complejidad de realidades en México.

Por lo que concierne a la historia, es necesario mencionar algunos casos representativos en zonas específicas del país como El Colegio de Michoacán (COL.MaCH, 1979) y El Colegio de la Frontera Norte (COLEF, 1982). Y en cuanto a la citada región del bajo río Bravo, han arrancado el Programa Noreste del Centro de Investigaciones y Estudios Superiores en Antropología Social (CIESAS), 1997, ubicado en Monterrey, y desde hace poco El Colegio de Tamaulipas (2002), espacios académicos donde se ha venido desarrollando una importante labor de investigación y publicación dirigida a indagar y difundir las variadas realidades históricas de sus respectivas regiones. Asimismo, recientemente se ha dado la apertura de licenciaturas y maestrías en historia en varios institutos de investigación especializados en la disciplina, como El Colegio de San Luis (1997). La estructura organizativa y el modelo académico de estos centros están basados en los de El Colegio de México (ColmeX, 1940). Así el panorama, ofrecer la licenciatura en Historia en una ciudad como Monterrey a mediados de los años setenta, puede verse como parte de aquel incipiente proceso de descentralización que aún se encuentra en marcha.

Además, ya desde la década de los sesenta los aspectos y problemáticas de las particularidades regionales reclamaban 
nuevas lecturas y análisis por parte de los historiadores en México. Como resultado de estas tendencias se han podido detectar dos obras trascendentes: Zapata y la revolución mexicana (1969) de John Womack y Pueblo en vilo, microbistoria de San José de Gracia (1968) de Luis González y González. Los procesos regionales comienzan a reclamar la atención de los historiadores ante las rígidas propuestas centralistas propias de la época postevolucionaria. ${ }^{33}$

De nuevo a Nuevo León. Es necesario señalar que la entonces UNL había hecho con anterioridad esfuerzos valiosos en este rubro al fundar el Departamento de Historia en 1952 bajo la dirección de Israel Cavazos Garza, así como la edición de publicaciones como revistas (Actas: Historia, Letras y Arte, Armas y Letras) y anuarios (Humanitas. Anuario del Centro de Estudios Humanisticos) donde se han publicado trabajos de investigación de autores tanto locales como de otros países. Especial atención merece esta última publicación, ya que ha acumulado un acervo de investigación histórica desde el año de 1960. De igual manera vale hacer mención de la creación, en la década de los ochenta, del Centro de Información de Historia Regional. Desde este lugar se ha pretendido dar impulso tanto a la historia del noreste como a otras expresiones artísticas y culturales de la región.

Al mismo tiempo, otros investigadores trabajan periodos de la historia regional en el ITESM desde los años sesenta, como lo atestiguan las ya mencionadas aportaciones de Eugenio del Hoyo e Isidro Vizcaya. A pesar de no contar con una oferta académica para formar historiadores, lo cual 200.

${ }^{33}$ Salmerón y Serrano, "Auge", 2003, pp. $185-$ no significa que sus estudiantes no cursen materias de historia, esta institución desde entonces respalda y promueve la investigación de varias disciplinas ubicadas en lo que se denomina humanidades o ciencias sociales.

Al fundarse el Colegio de Historia, uno de los problemas que debió encarar dicha institución fue la ausencia de profesionales en la disciplina. Así, una característica de la nueva etapa fue la llegada de historiadores extranjeros para comenzar la licenciatura, como es el caso del historiador argentino Mario Cerutti quien arriba a Monterrey en $1975 .{ }^{34}$ Debido a que este proyecto académico fue pionero en la entidad y en el noreste, ya que ni en Coahuila ni en Tamaulipas existía, la ausencia de profesionales en el campo de la historia supuso que la UANL convocara a los interesados para ocupar las plazas. ${ }^{35}$

La mencionada licenciatura en Historia ha tenido la característica de formar profesionales en el rubro de la historia económica, con especial atención a los procesos derivados del cambio de frontera, tras la guerra ante Estados Unidos a mediados del siglo XIX. De este modo, la acumulación de capitales mediante el tráfico comercial alrededor del bajo río Bravo, el notable desarrollo industrial o detectar la genealogía de las elites empresariales del noreste representan algunos de los temas para los nuevos profesionales. La intención era estudiar y analizar la realidad local y regional que tenía su origen más remoto a mediados de la centuria decimonónica,

${ }^{34}$ Espinosa, "Poder", 2004, pp. 21-22.

${ }^{35}$ Cabe señalar que desde 1963 con la fundación del Instituto de Investigaciones Históricas en la Universidad Autónoma de Tamaulipas ya se daban incipientes pasos hacía una profesionalización del oficio. 
momento histórico que cambiaría para siempre el contexto regional. ${ }^{36}$

Pero, si bien esa fue la tendencia en la propuesta de profesionalizar el oficio, se fueron desarrollando otras tendencias con preocupaciones específicas. De tal forma, también aparecen aportaciones historiográficas interesadas en la clase obrera, el desarrollo de su propia cultura y condiciones (Nuncio, Rojas, Palacios), cuyo esfuerzo se consumará con la creación de la Oficina de Investigación y Difusión del Movimiento Obrero (OIDMO), que publicará obras y promoverá el estudio de una problemática propiamente urbana. Con una preocupación parecida, aparecerán versiones con la pretensión de acercarse a sucesos relativamente recientes que han tenido que ver con algunas movilizaciones sociales que ocurrieron en el área metropolitana de Monterrey en las últimas décadas del siglo Xx. Ejemplo de esto es lo que plasma Sandra Arenal en Mujeres de tierra $y$ libertad.

En este nuevo universo del corpus historiográfico producido en la entidad se aprecian con toda claridad posicionamientos teóricos, conceptuales y metodológicos que podrían identificarse en dos sentidos: la visión marxista de la historia a partir de una lucha de clases y una lectura propia de la teoría de la dependencia.

Con lo anterior se pretende advertir, y para ello de nuevo cito a Zermeño, que no todo conocimiento o discurso sobre el pasado está sujeto a predisposiciones institucionales. Si bien la institución presupo-

${ }^{36}$ Para darse una idea de esto, se pueden revisar las publicaciones Siglo XIX. Revista de Historia y Siglo XIX. Cuadernos de Historia, cuyos proyectos han sido coeditados con el Instituto Mora durante algunos años de las décadas de los ochenta y los noventa. ne ciertas pautas para estudiar el pasado bajo aspectos específicos, no toda producción historiográfica está sujeta a esto. ${ }^{37} \mathrm{El}$ hecho de que aparezcan preguntas que apuntan hacia nuevos fenómenos e inéditas problemáticas vuelve posible la irrupción de distintas versiones acerca de la historia regional. Comenzar a estudiar fenómenos y problemáticas de sectores marginados -obreros, mujeres, migración a la ciudad, movilización ciudadana- distintos a los objetos de estudio trabajados desde un principio en la licenciatura en historia -burguesía local, acumulación de capitales, flujos productivos regionales, etc.-, muestran cómo se han ido abriendo vetas para la investigación histórica. Pues, la realidad sociohistórica de la entidad, y del país, a partir de los años setenta (crisis económica, emergencia de múltiples grupos y sectores, descentralización política) ha tenido su influjo en la forma como se escribe la historia. Pese a todo, estas aportaciones no acaban de recibir la atención debida para su desarrollo y difusión.

De los autores más leídos y citados que se ubican en este espacio se encuentran César Morado (Minería e industria pesada: capitalismo regional y mercado norteamericano, 1885-1910, 1991), Óscar Flores (Burguesía, militares y movimiento obrero en Monterrey, 1909-1923: revolución y comuna empresarial, 1991; El proceso de industrialización de la ciudad de Monterrey, 1940-1990, 1993), Abraham Nuncio (El grupo Monterrey, 1982; Visión de Monterrey, 1996) y el propio Cerutti (Economía de guerra y poder regional en el siglo XIX: gastos militares, aduanas y comerciantes en años de Vidaurri, 1855 1864, 1983; Burguesía, capitales e industria en el norte de México. Monterrey y su ámbito

${ }^{37}$ Zermeño, Cultura, 2002, p. 147. 
regional, 1850-1910, 1992). En esta nueva etapa, la obra de Mario Cerutti es la que lograr marcar la pauta. Particularmente llama la atención su propuesta respecto a la configuración y ubicación de un entorno geoeconómico a partir de una economía de guerra en un momento de doble coyuntura: la redefinición de la frontera entre México y Estados Unidos, así como la conformación de un reordenamiento regional en el noreste. En cuanto a investigación sobre historia regional, esta propuesta logra afianzar la idea del valor de las fuentes que resguardan los archivos municipales y estatales. Lo anterior como parte de ese proceso de descentralización que no sólo se deja ver en la oferta académica, sino también en los resultados de los estudios históricos en los cuales se descubren y reconocen las condiciones y circunstancias de las experiencias regionales. Si en otros momentos la preocupación de quienes se interesaban por el pasado era formar ciudadanos u organizar los esfuerzos de cronistas e historiadores, en esta fase el estudio de la historia ya realizado por profesionales respondería a tener un conocimiento de las múltiples y variadas experiencias sociohistóricas de las distintas realidades regionales. Lo anterior quizá ante el llamado de advertir $y$ diagnosticar tanto problemáticas como posibilidades de una pluralidad nacional que es necesario reconocer.

En general, una tendencia en esta etapa es investigar el desarrollo económico de Monterrey y sus periodos de industrialización comparándolo con zonas de otros países (País Vasco en España o la región de Piemonte-Lombardía-Liguria en Italia, por ejemplo) como lo presentan Mario Cerutti y Menno Vellinga (Burgzesías e industria en América Latina y Europa meridional, 1989).
Y por lo que corresponde a lo más representativo de la reciente historiografía regional, la memoria bistórica ahí plasmada resulta el referente que distingue a Monterrey. Por lo que es común, entonces, relacionarla con términos como "racionalidad", "progreso", "tecnología", "modernidad", "autonomía". Es ese el papel que la reciente historiografía le señala y confiere a la ciudad y a la entidad.

Asimismo, aunque en un ámbito que se extiende más allá de la entidad, cabe mencionar las aportaciones de Manuel Ceballos Ramírez, investigador del Colegio de la Frontera Norte en Nuevo Laredo que ha trabajado sobre la conformación bistốrica de la frontera norte; de Octavio Herrera Pérez, investigador del Colegio de Tamaulipas en Ciudad Victoria que ha estudiado el proceso de la zona libre en la frontera norte del país, o de Cuauhtémoc Velasco Ávila y Martha Rodríguez García, quienes han investigado, desde Saltillo, sobre el encuentro entre nómadas y civilizados en el noreste. Esto propone advertir que desde las otras dos entidades ubicadas en el noreste mexicano, la práctica del oficio apuntaría a considerar dicha región como un ente histórica y socialmente singular que ha compartido ciertas experiencias y procesos.

En los últimos años, y luego de la salida de la Facultad de Filosofía y Letras, que no de la UANL, de Mario Cerutti a principios del año 2000 , la "nueva" dirección que se ha pretendido tomar en dicha institución respecto al plan de estudios para formar historiadores apunta hacia el ejercicio de una historia cultural. Es decir, se quiere enfocar los estudios hacia otros horizontes de investigación como puede ser la hermenéutica y el análisis de textos de historia o sobre la sociología del cono- 
cimiento del pasado, considerando el empleo de enfoques teóricos y metodológicos propuestos por autores, entre otros, como Certeau, Ricoeur, Foucault o Luhmann. La tarea, según parece ser, es abrir los estudios históricos a otros paradigmas y modelos de estudio e investigación, aunque hasta el momento sigue sin aparecer alguna investigación que sea considerada un "parteaguas" en la manera de hacer esta "nueva" historia.

Existen otras instituciones que en las décadas más recientes han respaldado la investigación y publicación de este tipo de estudios, con lo que se ha enriquecido la producción historiográfica regional. Cabe mencionar aquí a la Universidad de Monterrey (UdeM, 1969), al Archivo General del Estado de Nuevo León (AGENL), al Consejo para la Cultura y las Artes de Nuevo León (CONARTE, 1995), así como las publicaciones que han hecho importantes grupos editoriales con motivo de los 400 años de Monterrey en el año de $1996 .^{38}$ Este evento representa el punto con el que se propone cerrar el largo proceso de la producción historiográfica regional aquí abordado.

De igual manera, la fundación de agrupaciones - tanto de historiadores profesionales como de cronistas y aficionados a la historia-, como la Asociación de Historiadores Profesionales del Noreste de México (ADHINOR, 1985), el Colegio de Historiadores y Cronistas de Nuevo

\footnotetext{
${ }^{38}$ Fue el caso de la editorial Grijalbo, Ediciones Minas Viejas y El Diario de Monterrey, por citar algunas. En estas condiciones se han reeditado obras que durante un buen tiempo estuvieron en el olvido y abandono, como puede ser el caso de Monterrey, un vistazo a sus entrañas de Máximo de León.
}

León y la Asociación de Historia Económica del Norte de México (AHENME), continúa propiciando el debate e intercambio de ideas respecto al rumbo que debe tomar el oficio de historiar en Nuevo León y en la región noreste de México.

Asimismo, los contactos y reuniones entre los profesionales del oficio en México se han vuelto más constantes y formalizados, tanto por la organización que han sabido desarrollar y mantener como por el respaldo de las instituciones en las que los historiadores se desenvuelven.

\section{A MANERA DE CONCLUSIÓN}

De forma preliminar es posible tener en cuenta algunas consideraciones de la propuesta periódica esbozada. Si bien se ha construido un ámbito donde el conocimiento histórico se viene elaborando desde hace más de un siglo en Nuevo León, se advierten ciertas particularidades: la instauración de una institución personal encarnada por el erudito decimonónico doctor González, quien no sólo escribió sobre historia; la puesta en marcha del Colegio Civil con su proyecto académico; la fundación de agrupaciones - a partir del legado intelectual y académico de aquellos personajes-que representan los primeros intentos por instituir espacios dedicados a los estudios científicos, entre ellos de historia (Sociedad Científico-Literaria José Eleuterio González); la formalización en el siglo Xx de instituciones con variados perfiles (universidades, asociaciones, editoriales, entre otras) que comienzan a difundir el conocimiento de la historia regional (seminarios, coloquios, encuentros, conferencias, publicaciones); así como la formación académica de los primeros historiadores 
locales al comenzarse a impartir la disciplina en la UANL.

El ejercicio historiográfico desarrollado en Nuevo León ha estado, por supuesto, en contacto con lo que se producía y circulaba en otras regiones del país -en especial con la ciudad de México como centro cultural e intelectual-y del extranjero -tanto la historia generada en Estados Unidos como la presentada por aquellos extranjeros que han radicado en Monterrey.

Si bien el corpus historiográfico nuevoleonés ha generado un conocimiento importante, este se ha centrado en explicar situaciones como la industrialización y la genealogía burguesa local, por lo que algunos aspectos históricos, sociales y políticos han quedado de lado o, si hay estudios al respecto, no cuentan con la difusión debida. Ejemplo de esto lo representan movimientos sociales de las décadas recientes (grupos marginales, migración a la ciudad, pluralidad política), actuación de grupos y organizaciones urbanas (movilización social, guerrilla), condición de la clase obrera (luchas y reivindicaciones sindicales, cultura popular) o problemáticas en torno al género.

Asimismo, lo más representativo de la historiografía producida en la entidad ha optado la mayoría de las veces por realizar un trabajo de historia con el uso del archivo como su principal fuente; documentos relativos a decretos, misivas, periódico oficial, actas, etc., resultan ser lo más socorrido para realizar la reconstrucción del pasado. Así, la consideración de otro tipo de fuentes como podría ser lo visual (grabados, imágenes, fotografías) o lo oral (entrevistas, historias de vida) se encuentran, en el mejor de los casos, en un lugar secundario.
Lo anterior, valga decirlo, responde a una situación como la que ha vivido la ciudad de Monterrey desde hace poco más de un siglo; el auge industrial y económico que la ha dinamizado propicia, en cierto grado, que ese sector que llevó a cabo dicho proceso guarde celosa memoria de lo sucedido. Tan es así que recientemente se ha propuesto elaborar una arqueología industrial en torno a la experiencia de la Fundidora de Fierro y Acero de Monterrey. Sería esto lo que desde un punto de vista histórico y social es aceptado y reconocido como un tipo de cultura propiamente local. En tal sentido, es posible mencionar lo que se considera como una cultura norestense, resaltando lo realizado por comerciantes, empresarios y hombres de negocios de la región desde la segunda mitad del siglo XIX al seguir las investigaciones publicadas en tales rubros.

Pero lo anterior no implica que toda la producción historiográfica se venga encontrando sujeta a tales condiciones. Se trata, en todo caso, de la elaboración de un tipo de conocimiento bistórico en el cual, si bien muestra cierta uniformidad en cuanto a los temas tratados y métodos empleados, han aparecido múltiples lecturas respecto al pasado regional. En tal sentido, lo que se deja ver en los estudios recientes de historia en Nuevo León apuntaría hacia un tipo de eclecticismo académico, a partir del cual múltiples y variados paradigmas apenas estarían siendo contemplados y utilizados. Ejemplo de esto puede ser el caso de recientes investigaciones sobre la concepción y usos de los espacios públicos durante el porfiriato empleando fuentes distintas a las tradicionales como es el caso de material visual (González Maíz). Ello implicaría que se comienzan a plan- 
Épocas y autores en la historiografía en Nuevo León 1867-1996a

Prolegómenos
(1867-1925)
José Eleuterio
González
(1813-1888)
Hermenegildo Dávila
(1846-1908)
Rafael Garza Cantú
(1864-1912)

Regionalismo

(1925-1942)

Vito Alessio Robles

(1879-1957)

David Alberto Cossío

(1883-1939)

Santiago Roel Melo

(1885-1957)

Miguel Martínez

Rendón

(1891-1966)
Institucionalización

(1942-1974)

José Pedro Saldaña

(1891-1992)

Carlos Pérez-

Maldonado

(1896-1990)

Héctor González

(1882-1948)

Raúl Rangel Frías

(1913-1993)

Eugenio del Hoyo

Cabrera

(1914-1989)

Isidro Vizcaya Canales

(1917-2005)

Israel Cavazos Garza

(n. 1923)

Rodrigo Mendirichaga

(n. 1931)

Máximo de León Garza

(1931-2001)
Profesionalización

(1974-1996)

Abraham Nuncio

Limón

(n. 1941)

Mario Cerurti

(n. 1941)

Óscar Flores Torres

(n. 1960)

Antonio Olvera

Sandoval

(n. 1962)

César Morado Macías

(n. 1969)

a La intención es presentar a algunos de los cronistas e historiadores que han contribuido en la gestación y evolución de la historiografía regional según las condiciones institucionales, académicas y profesionales sucedidas en el estado. Cualquier omisión es involuntaria.

Fuente: Espinosa, "Poder", 2004.

tear nuevas formas para investigar problemáticas y objetos de estudio.

Por último, otra circunstancia particular que es necesario advertir es la notoria centralidad de actividades regionales en un solo polo, Monterrey; poderosos emporios, influyentes medios de comunicación, así como instituciones académicas se encuentran en la citada ciudad donde acaparan la mayor parte de los quehaceres de la entidad (político, económico, cultural, académico, etc.). De este modo, al hablar de Monterrey muy bien se puede hacer referencia a Nuevo León. Centrándome en la actividad historiográfica regional, cabe advertir que la parte sustancial de dicho corpus se ha realizado desde allí. 


\section{BIBLIOGRAFÍA}

-Arias Gómez, María Eugenia, "Dimensión historiográfica regional en México (1890-1915)", tesis de doctorado en Historia, UNAM, México, 2005.

-Cavazos, Israel, Estado de Nuevo León y ciudad de Monterrey, Enciclopedia de México, México, 1976 (sobretiro especial para el H. Ayuntamiento de Monterrey).

-Ceballos Ramírez, Manuel, Historiografía nuevoleonesa, Archivo General del Estado de Nuevo León, Monterrey, 1995 (Orgullosamente Bárbaros, 7). - Cuatro estados y una frontera. Tamaulipas, Nuevo León, Coabuila y Texas en su colindancia territorial a fines del siglo XIX y szis consecuencias cien años después, UANL/Universidad Autónoma de Tamaulipas, Monterrey, 1999.

- Historiadores. Cincuenta años de reuniones internacionales: 1949-1999. Memorias de la Primera Reunión de Historiadores Mexicanos y Norteamericanos, Monterrey, 1949, UANL/Universidad Autónoma de Tamaulipas/COLEF/SEP-Coahuila/Nacional Park Service, Monterrey, 1999.

, "Consideraciones históricas sobre la conformación de la frontera norte mexicana" en José Manuel Valenzuela Arce (coord.), Por las fronteras del norte. Una aproximación cultural a la frontera México-Estados Unidos, CONACULTA/ FCE, México, 2003 (Biblioteca Mexicana).

-Certeau, Michel de, La escritura de la historia, trad. Jorge López Moctezuma, Universidad Iberoamericana, México, 1993.

-Cerutti, Mario, Burguesia, capitales e industria en el norte de México. Monterrey y su ámbito regional (1850-1910), Alianza Editoral/UANL, México, 1992. y Miguel Ángel González Quiroga (comps.), Frontera e bistoria económica. Texas y el norte de México (1850-1865), Instituto Mora/ UAM, México, 1993.
-Cuello, José, El norte, el noreste y Saltillo en la historia colonial de México, Archivo Municipal de Saltillo/H. Ayuntamiento de Saltillo, Saltillo, 1990.

-Cossío, David Alberto, Historia de Nuevo León. Evolución política y social, Talleres Linotipográficos de J. Cantú Leal, Monterrey, 19251933, tr. I-VI.

-Elias, Norbert, El proceso de la civilización. Investigaciones sociogenéticas y psicogenéticas, FCE, México, 1994.

-Espinosa Martínez, Edgar Iván, "Poder político, desarrollo económico y conciencia regional. Instituciones e intelectuales en la moderna historiografía de Nuevo León", tesis de maestría en Sociología Política, Instituto Mora, México, 2004.

-Foucault, Michel, La arqueología del saber, trad. Aurelio Garzón del Camino, Siglo XXI, México, 2001.

-Gadamer, Hans-Georg, Verdad y método, Ediciones Sígueme, Salamanca, 2001.

-García Ortega, Roberto, Monterrey y Saltillo, bacia un modelo de planeación y gestión urbana metropolitana, Colegio de la Frontera Norte/Universidad Autónoma de Coahuila, Tijuana, 2003.

-Garza Cantú, Rafael, Algunos apuntes acerca de las letras y la cultura de Nuevo León, en la centuria de 1810 a 1910, ConaculTa/Gobierno del Estado de Nuevo León, México, 1995.

-González, Héctor, Historia del Colegio Civil, Universidad de Nuevo León, Monterrey, 1945.

- Siglo y medio de cultura nuevoleonesa, Ediciones Botas, México, 1946.

-González y González, Luis, La ronda de las generaciones, Editorial Clío/El Colegio Nacional, México, 1997.

-Herrera, Octavio, La zona libre. Excepción fiscal y conformación histórica de la frontera norte de México, SRE, México, 2004.

-Matute, Álvaro, "Notas sobre la historiografía positivista mexicana", Secuencia. Revista de 
Historia y Ciencias Sociales, núm. 21, septiembrediciembre de 1991, México, pp. 49-64.

-Mauro, Frédéric, "Le développement économique de Monterrey, 1890-1960", Caravelle, Cabiers du Monde Hispanique et Luso-Brésilien, Brasil, 1964.

-Morado Macías, César, "Historia de Nuevo León. Apuntes epistemológicos para una historiografía reciente", Provincias Internas, año 1, núm. 3, otoño de 2001, Saltillo, pp. 15-31.

-Pi-Suñer, Antonia, "La generación de Vicente Riva Palacio y el quehacer historiográfico", Secuencia. Revista de Historia y Ciencias Sociales, núm. 35, mayo-agosto de 1996, México, pp. 83-108.

-Ruiz Solís, Francisco, "Apuntes para la historia del pensamiento científico en Nuevo León" en Miguel Covarrubias (ed.) y Erick Estrada (fotografía), Desde el cerro de la Silla. Artes y Letras de Nuevo León, UANL, Monterrey, 1992.

-Salmerón Sanginés, Pedro y Pablo Serrano Álvarez, "El auge de la historiografía política regionalista en México, 1968-2000. Revisionismo y análisis político", Secuencia. Revista de Historia y Ciencias Sociales, núm. 57, septiembre-diciembre de 2003, México, pp. 185-200.

-Saragoza, Alex M., The Monterrey Elite and the Mexican State, 1880-1940, University of Texas Press, Austin, 1988.

Vellinga, Menno, Industrialización, burguesía y clase obrera en México: el caso de Monterrey, trad. José Sernaudi, Siglo XXI, 2a. ed., México, 1981.

- Vizcaya Canales, Isidro, Los orígenes de la industrialización de Monterrey. Una bistoria económica y social desde la caída del segundo imperio basta el fin de la revolución (1867-1920), Archivo del Gobierno del Estado de Nuevo León, Monterrey, 2001.

-Zermeño, Guillermo, La cultura moderna de la historia. Una aproximación teórica e bistoriográfica, Colmex, México, 2002. 